\title{
DEPARTMENT OF ANAESTHESIA DIRECTOR OF OBSTETRIC ANAESTHESIA
}

Academic Anaesthetist required to direct the Division of Obstetric Anaesthesia at the University of Alberta, and the Capital Health Authority (Region 10) in Edmonton, Alberta.

To be eligible for consideration, candidates must qualify for licensure in the province of Alberta and must be certified by the Royal College of Physicians and Surgeons of Canada. Special consideration will be given to candidates with subspecialty training or extensive clinical experience in obstetric anaesthesia. To be eligible, candidates must have a background in research, administration and resident education.

The University appointment would be at the Assistant/Associate Professor level and the successful applicant would dedicate about $50 \%$ of their time to clinical work and the remaining $50 \%$ between teaching, research and administration.

The successful candidate would be expected to organize an effective obstetric anaesthesia service in the Edmonton region (approximately 14,000 deliveries per year), and to play a leadership role in research and education in the subspecialty division.

Remuneration for GFT's would be in accordance with the usual recommendation for Assistant/Associate Professors at the University of Alberta. (Salary range: Assistant Professor $\$ 39,230-55,526$; Associate Professor $\$ 48,572-69,664)$, plus competitive fee-for-service income generated from $50 \%$ clinical practice.

In accordance with Canadian Immigration requirements, this advertisement is directed to Canadian citizens and permanent residents.

The deadline for applications is July 31 , 1995. Interested individuals are invited to send a curriculum vitae, including the names of three references, to:

Dr. B.T. Finucane, Chairman, Department of Anaesthesia, Room: 3 B2.32

Walter C. Mackenzie Health Sciences Centre, Edmonton, Alberta T6G 287.

Telephone: (403) 492-8887 Fax: (403) 492-9610

The University of Alberta is committed to the principle of equity in employment. As an employer we welcome diversity in the workplace and encourage applications from all qualified women and men, including Aboriginal peoples, persons with disabilities, and members of visible minorities.

\section{同: \\ PIEDMONT \\ INSTITUTE of PAIN \\ MANAGEMENT \\ COMPETITIVE AWARDS FOR RESEARCH RELATED TO CHRONIC AND ACUTE PAIN SYNDROME}

Applications are being accepted from licensed physicians who will be engaged in clinical or basic science research as it relates to pain management. The applicant must provide a research plan with a projected date of completion. The results of the research must be presented in a format that is publishable in a refereed medical journal. In addition, a financial representative must be designated as well as a description of the facilities available to complete the proposed research plan.

The Piedmont Institute of Pain Management is a tax-exempt corporation which is making funds available to encourage continued research in the management of chronic pain. The awards are given regardless of race, creed, gender, religion or geographical location. Deadline for application is October $31,1995$.

Application guidelines may be obtained by corresponding with:

Piedmont Institute of Pain Management

Research Committee

3333 Silas Creek Parkway

Winston-Salem, NC 27103, U.S.A.

Phone (910) 718-2830 